\title{
Doping Effect on Magnetism of Thiolate-Capped 25-Atom Alloy Nanoclusters
}

Yingwei Li, ${ }^{1,+}$ Saborni Biswas, ${ }^{1,+}$ Tian-Yi Luo, ${ }^{2}$ Rosalba Juarez-Mosqueda, ${ }^{3}$ Michael G. Taylor, ${ }^{3}$ Giannis Mpourmpakis, ${ }^{3}$ Nathaniel L. Rosi, ${ }^{2}$ Michael P. Hendrich, ${ }^{1,}{ }^{*}$ and Rongchao Jin ${ }^{1, *}$

1Department of Chemistry, Carnegie Mellon University, Pittsburgh, Pennsylvania 15213, United States

2Department of Chemistry, University of Pittsburgh, Pittsburgh, Pennsylvania 15260, United States ${ }^{3}$ Department of Chemical Engineering, University of Pittsburgh, Pittsburgh, Pennsylvania 15261, United States

\section{Synthesis}

To prepare $\left[\mathrm{Au}_{25-x} \mathrm{Ag}_{x}(o-\mathrm{EBT})_{18}\right]^{-}(x=4-7) \mathrm{NCs}, 8.62 \mathrm{mg} \mathrm{AgNO}_{3}, 80 \mathrm{mg} \mathrm{HAuCl}_{4} \cdot 3 \mathrm{H}_{2} \mathrm{O}$ (with $\mathrm{Ag} / \mathrm{Au}$ molar ratio $=1: 4$ ), and $82 \mu \mathrm{L} o$-EBT were mixed in THF and vigorously stirred for 30 min. Then, a freshly prepared aqueous solution of $\mathrm{NaBH}_{4}(144 \mathrm{mg}$ in $5 \mathrm{ml}$ ice-cold water) was added. After $1 \mathrm{~h}$, the crude product was washed by methanol to remove water and excess thiol. In the second time, $\left[\mathrm{Au}_{25-x} \mathrm{Ag}_{x}(\mathrm{o} \text {-EBT })_{18}\right]^{-} \mathrm{NCs}$ were extracted in methanol. Decreasing the Ag/Au molar ratio to 1:8 did not decrease the Ag doping amount $x$ in [Au25$\left.{ }_{x} \mathrm{Ag}_{x}(o \text {-EBT })_{18}\right]^{-}$. Replacing $o$-EBT with $o$-MBT resulted in $\left[\mathrm{Au}_{25-x} \mathrm{Ag}_{x}(o-\mathrm{MBT})_{18}\right]^{-}(x=4-7)$. The obtained [ $\left.\mathrm{Au}_{25-x} \mathrm{Ag}_{x}(o-E B T)_{18}\right]^{-}$was dissolved in $5 \mathrm{~mL} \mathrm{CH}_{2} \mathrm{Cl}_{2}$, and stirred in the presence of excess silica gel (pore size $60 \AA, \sim 300 \mathrm{mesh}$ ) for $15 \mathrm{~min}$, resulting in neutral $\left[\mathrm{Au}_{25-x} \mathrm{Ag}_{x}(o-\mathrm{EBT})_{18}\right]^{0}$ or $\left[\mathrm{Au}_{25-x} \mathrm{Ag}_{x}(o-\mathrm{MBT})_{18}\right]^{0}$. Plate-shaped crystals were obtained via layer diffusion of hexane into the $\mathrm{CH}_{2} \mathrm{Cl}_{2}$ solution of the NCs within 2 days.

To prepare a series of $\left[\mathrm{Au}_{25-x} \mathrm{Ag}_{x}(\mathrm{PET})_{18}\right]^{-}$NCs with different ranges of $x$, precursors of different $\mathrm{Ag} / \mathrm{Au}$ molar ratio were used (Table S1), mixed with $130 \mathrm{mg}$ TOABr, $150 \mu \mathrm{L}$ PET in THF and vigorously stirred for $30 \mathrm{~min}$. Then, an aqueous solution of $\mathrm{NaBH}_{4}(77 \mathrm{mg}$ in 5 $\mathrm{ml}$ ice-cold water) was added. After reaction overnight, the crude product was washed by methanol twice, and then extracted by acetonitrile.

Table S1. The Ag/Au ratios in precursors.

\begin{tabular}{ccccc}
\hline Sample & $\mathrm{HAuCl}_{4} \cdot 3 \mathrm{H}_{2} \mathrm{O}(\mathrm{mg})$ & $\mathrm{AgNO}_{3}(\mathrm{mg})$ & $\mathrm{Ag} / \mathrm{Au}$ molar ratio & $x$ in $\left[\mathrm{Au}_{25-x} \mathrm{Ag}_{x}(\mathrm{PET})_{18}\right]^{q}$ \\
\hline $\mathrm{A}$ & 80 & 0 & $0: 100$ & 0 \\
\hline $\mathrm{B}$ & 80 & 0.34 & $1: 100$ & $0-2$ \\
\hline $\mathrm{C}$ & 80 & 0.99 & $1: 35$ & $0-6$ \\
\hline $\mathrm{D}$ & 80 & 4.31 & $1: 8$ & $3-7$ \\
\hline $\mathrm{E}$ & 80 & 8.62 & $1: 4$ & $5-9$ \\
\hline
\end{tabular}


The obtained [ $\left.\mathrm{Au}_{25-x} \mathrm{Ag}_{x}(\mathrm{PET})_{18}\right]^{-} \mathrm{NCs}$ with different $\mathrm{Ag}$ doping (NCs $\sim 20 \mathrm{mg}$ ) were further dissolved in $5 \mathrm{~mL} \mathrm{CH} \mathrm{Cl}_{2}$, and stirred in the presence of excess silica gel for $15 \mathrm{~min}$ to obtain the corresponding $\left[\mathrm{Au}_{25-x} \mathrm{Ag}_{x}(\mathrm{PET})_{18}\right]^{0}$.

\section{Single crystal crystallography}

Single crystal X-ray diffraction data of $\mathbf{A u}_{19.2} \mathbf{A g}_{5.8}(\boldsymbol{o}-\mathbf{E B T})_{18}$ was collected on a Bruker X8 Prospector Ultra equipped with an Apex II CCD detector and an I $\mu \mathrm{S}$ micro-focus $\mathrm{CuK} \alpha \mathrm{X}$-ray source $(\lambda=1.54178 \AA)$. A piece of dark red block crystal with dimensions $0.08 \times 0.04 \times 0.02$ $\mathrm{mm}$ was mounted onto a MiTeGen MicroMount. Data collection was performed at $230 \mathrm{~K}$. A trigonal unit cell with $\mathrm{a}=16.7728(14) \AA, \mathrm{b}=24.4188(19) \AA, \mathrm{c}=21.8661(17) \AA, \alpha=90^{\circ}, \beta=$ $91.092(4)^{\circ}, \gamma=90^{\circ}$ was determined using the least-square refinement. The frames were integrated with the Bruker SAINT software package. ${ }^{51} 51847$ reflections in the range $5.426^{\circ}$ $<2 \theta<136.874^{\circ}$ were found, of which 15803 were independent (average redundancy 3.28, completeness $=96.0 \%$, Rint $=5.50 \%$, Rsigma $=5.35 \%$ ) Data were corrected for absorption effects using SADABSs1 Multi-Scan method $\left(\mathrm{T}_{\min }=0.353, \mathrm{~T}_{\max }=0.753\right)$. Monoclinic space group P2 $1 / \mathrm{n}$ was determined based on systematic absences. The structure was solved by intrinsic phasing using the Bruker SHELXTs2 software package and refined by full-matrix least-squares on $\mathrm{F}^{2}$ using SHELXL ${ }^{\mathrm{s3}}$ in Olex2..$^{4}$ The asymmetric unit contains one half of an $\mathbf{A u}_{19.2} \mathbf{A g}_{5.8}$ (o-EBT) ${ }_{18}$ cluster. All the metal sites (13) and S atoms (9) were found directly. Remaining non-hydrogen atoms were generated via subsequent difference Fourier syntheses. Au, Ag occupancies at all of the 13 different metal sites (see table below) were obtained by refinement with free variables. EXYZ, EADP were used to constrain the Ag and $\mathrm{Au}$ atoms at the same sites. SIMU, RIGU restraints and DFIX constraint were used to refine carbon atoms. All non-hydrogen atoms were refined with anisotropic displacement parameters. Idealized hydrogen atom positions were calculated.

Table S2. The occupancy of Au/Ag on the icosahedral $\mathrm{M}_{12}$ shell.

\begin{tabular}{cc|cc|cc}
\hline Atom & Occupancy & Atom & Occupancy & Atom & Occupancy \\
\hline $\mathrm{Au} 1$ & 0.646 & $\mathrm{Au} 6$ & 0.631 & $\mathrm{Au} 12$ & 0.361 \\
\hline $\mathrm{Ag} 1$ & 0.354 & $\mathrm{Ag} 6$ & 0.369 & $\mathrm{Ag} 12$ & 0.639 \\
\hline $\mathrm{Au} 3$ & 0.537 & $\mathrm{Au} 9$ & 0.589 & $\mathrm{Au} 13$ & 0.329 \\
\hline $\mathrm{Ag} 3$ & 0.463 & $\mathrm{Ag} 9$ & 0.411 & $\mathrm{Ag} 13$ & 0.671 \\
\hline
\end{tabular}

\section{EPR simulation}

The simulation software SpinCount was written by one of the authors. ${ }^{55}$ The software diagonalizes the electronic terms of the spin Hamiltonian: $H=\beta S \cdot g \cdot B+S \cdot D \cdot S+S . A . I-$ gn $\beta \mathrm{nB} \cdot \mathrm{I}+\mathrm{I} \cdot \mathrm{P} \cdot \mathrm{I}$, where the parameters have the usual definitions, ${ }^{\mathrm{s} 6}$ and performs leastsquares fitting of simulations to the spectra. The quantitative simulations are generated with consideration of all intensity factors, which allows the computation of simulated spectra for a specified sample concentration. 
Table S3. Parameters for simulations of EPR signals shown in Figure 4/6.

\begin{tabular}{|c|c|c|c|c|c|c|c|}
\hline & & $g_{\mathrm{x}}$ & $g_{\mathrm{y}}$ & $g_{\mathrm{z}}$ & $\sigma_{\mathrm{x}}$ & $\sigma_{\mathrm{y}}$ & $\sigma_{\mathrm{z}}$ \\
\hline \multirow{5}{*}[\mathrm{Au}_{25-x}\operatorname{Ag}_{x}(\mathrm{PET})_{18}]{$^{0}$} & $x=0$ & 2.62 & 2.31 & 1.81 & 0.136 & 0.149 & 0.062 \\
\hline & $x=0-2$ & 2.62 & 2.25 & 1.81 & 0.131 & 0.132 & 0.062 \\
\hline & $x=0-6$ & 2.52 & 2.19 & 1.81 & 0.090 & 0.072 & 0.055 \\
\hline & $x=3-5$ & 2.51 & 2.23 & 1.83 & 0.120 & 0.107 & 0.076 \\
\hline & $x=5-9$ & 2.38 & 2.25 & 1.80 & 0.107 & 0.182 & 0.059 \\
\hline$\left[\mathrm{Au}_{25-x} \operatorname{Ag}_{x}(o-E B T)_{18}\right]^{0}$ & $x=4-7$ & 2.34 & 2.20 & 1.84 & 0.095 & 0.141 & 0.064 \\
\hline
\end{tabular}

\section{Computational methods}

Structure optimizations and photoabsorption spectrum calculations were carried out for the $\left[\mathrm{Au}_{19} \mathrm{Ag}_{6}(\mathrm{o}-\mathrm{EBT})_{18}\right]^{q},\left[\mathrm{Au}_{19} \mathrm{Ag}_{6}(\mathrm{PET})_{18}\right]^{q}$, and $\left[\mathrm{Au}_{25}(\mathrm{PET})_{18}\right]^{q}$ NCs (with $q=-1,0$ for $\left[\mathrm{Au}_{19} \mathrm{Ag}_{6}(\mathrm{PET})_{18}\right]^{q}$ and $\left[\mathrm{Au}_{25}(\mathrm{PET})_{18}\right]^{q}$, and $q=-1,0$, and +1 for $\left[\mathrm{Au}_{19} \mathrm{Ag}_{6}(o-\mathrm{EBT})_{18}\right]^{q}$, respectively) within the framework of density functional theory (DFT) and time-dependent DFT using the PBE functional. ${ }^{77}$ All the calculations were performed using a real-space grid with spacing of $0.2 \AA$ in GPAW. ${ }^{88,59}$ All methods for the thermodynamic stability for doped metal NCs are exactly as described in our previous work. ${ }^{s 10,511}$ Briefly, the Turbomoles12 computational package was used to relax all structures at the BP-86 $6^{s 13,514}$ exchangecorrelation density functional with the def2-SV(P) basis set. ${ }^{s 15, s 16}$ Following geometry relaxation, single point energy evaluations on the isolated core and shell regions were used to calculate both the shell-to-core binding energy (BE) and core cohesive energy (CE) for each structure. 


\section{Supporting Figures}

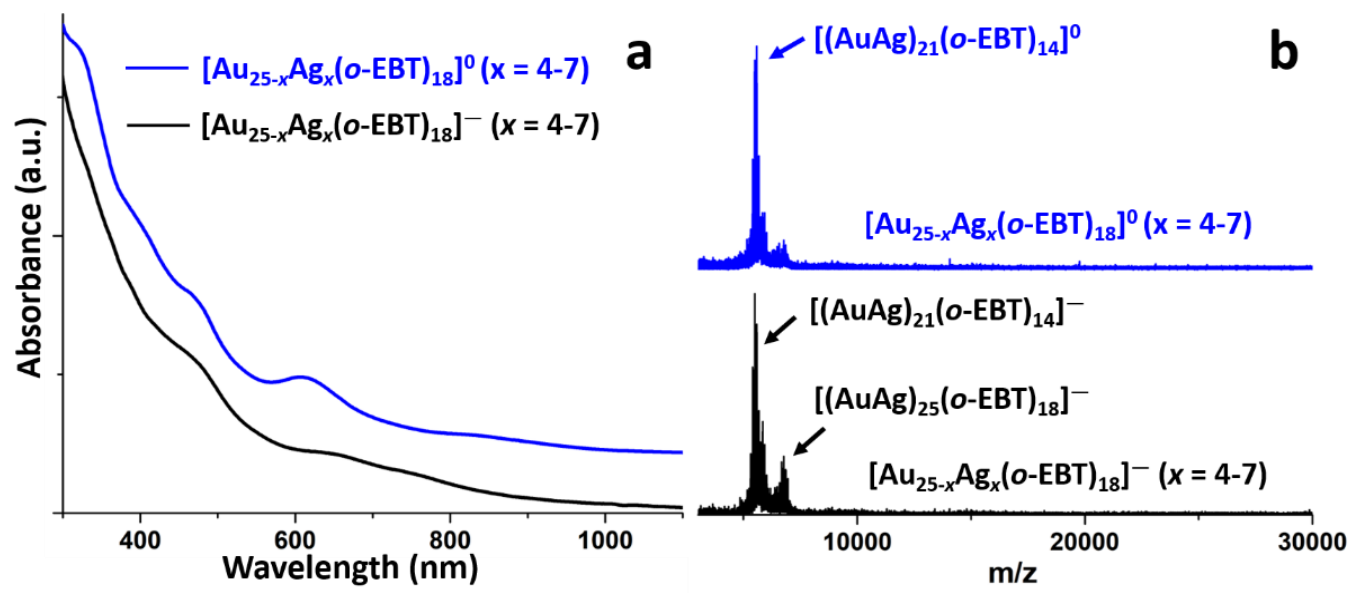

Figure S1. (a) UV-vis and (b) MALDI-MS spectra of $\left[\mathrm{Au}_{25-x} \mathrm{Ag}_{x}(o-\mathrm{EBT})_{18}\right]^{q}(q=-1$ (black) or 0 (blue)). In panel a), the spectra are upward shifted for the ease of comparison.

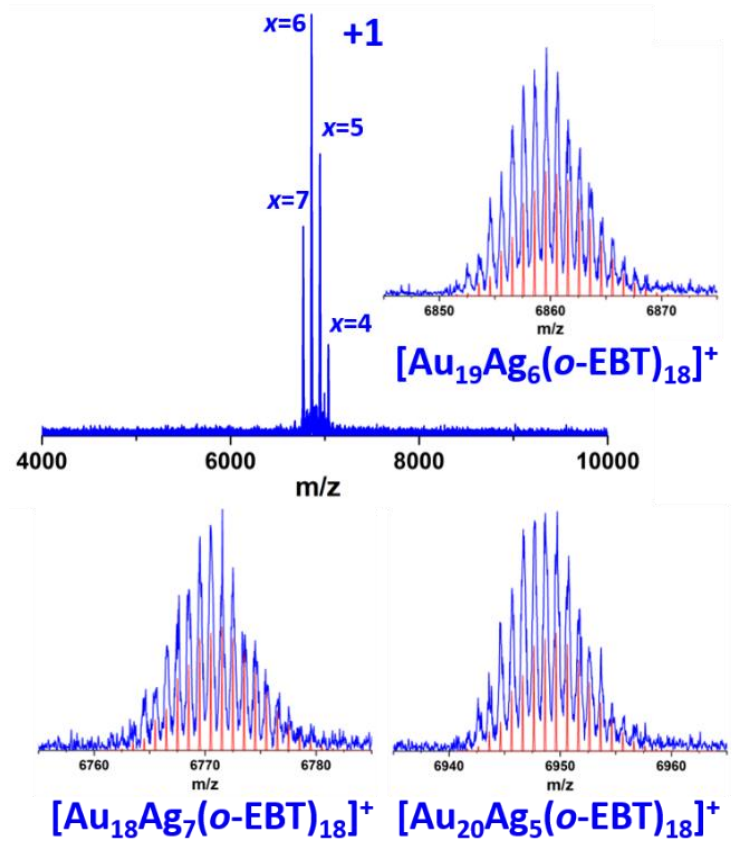

Figure S2. ESI-MS spectrum of $\left[\operatorname{Au}_{25-x} A_{g_{x}}(o \text {-EBT })_{18}\right]^{0}(x=4-7)$ with the experimental isotope patterns (blue) and calculated ones (red) (e.g. when $\mathrm{x}=6$, exp. $\mathrm{m} / \mathrm{z}=6859.56$, cal. $\mathrm{m} / \mathrm{z}=$. The +1 charge is in-source ionization (no ligand loss). 

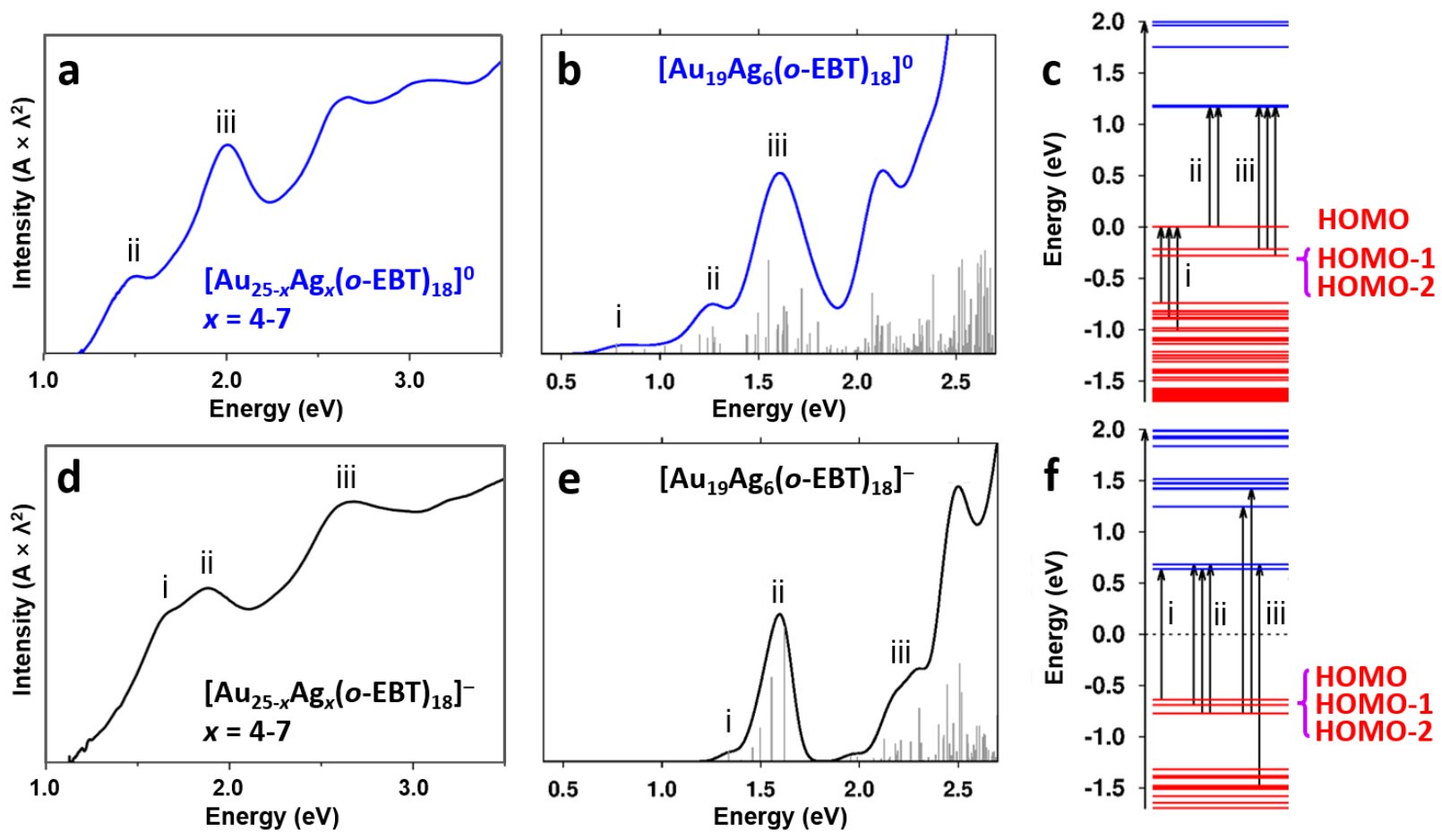

Figure S3. (a) Experimental spectrum of neutral $\left[\operatorname{Au}_{25-x} \operatorname{Ag}_{x}(O-E B T)_{18}\right]^{0}(x=4-7)$, (b) calculated absorption spectrum of the most abundant species $\left[\mathrm{Au}_{19} \mathrm{Ag}_{6}(o-\mathrm{EBT})_{18}\right]^{0}$, and (c) corresponding KS diagram. (d) Experimental spectrum of anionic [Au25-xAg $\left.\left.\mathrm{A}_{x}(o-\mathrm{EBT})_{18}\right)_{18}\right]^{-}$ $(x=4-7)$, (e) calculated absorption spectrum of $\left[\mathrm{Au}_{19} \mathrm{Ag}_{6}(o-\mathrm{EBT})_{18}\right]^{-}$, and (f) corresponding KS diagram.

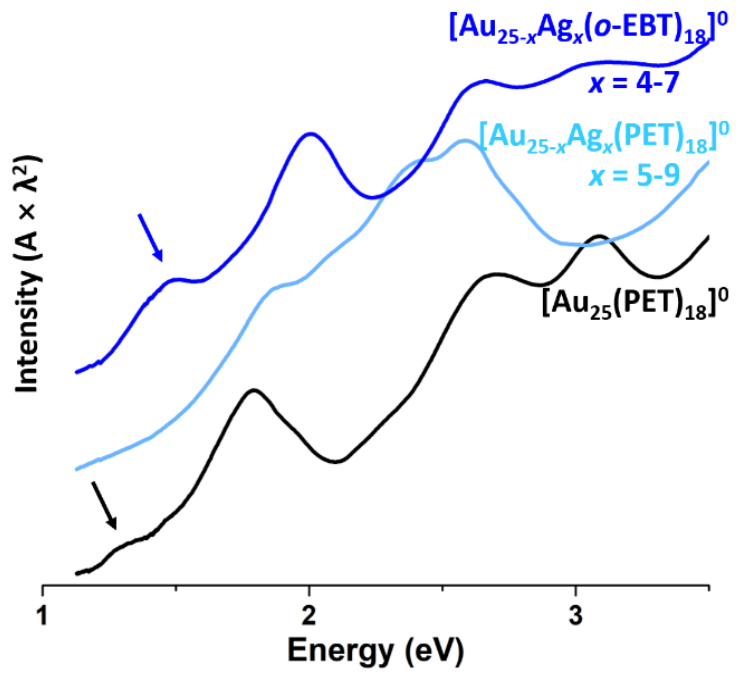

Figure S4. UV-vis spectra on energy scale: (blue) $\left[\mathrm{Au}_{25-x} \mathrm{Ag}_{x}(o-\mathrm{EBT})_{18}\right]^{0}(x=4-7)$, (cyan) $\left[\operatorname{Au}_{25-x} \operatorname{Ag}_{x}(\mathrm{PET})_{18}\right]^{0}(x=5-9)$, and (black) $\left[\mathrm{Au}_{25}(\mathrm{PET})_{18}\right]^{0}$. Arrows indicate the absorption peak at low energy due to Jahn-Teller-like distortion. 


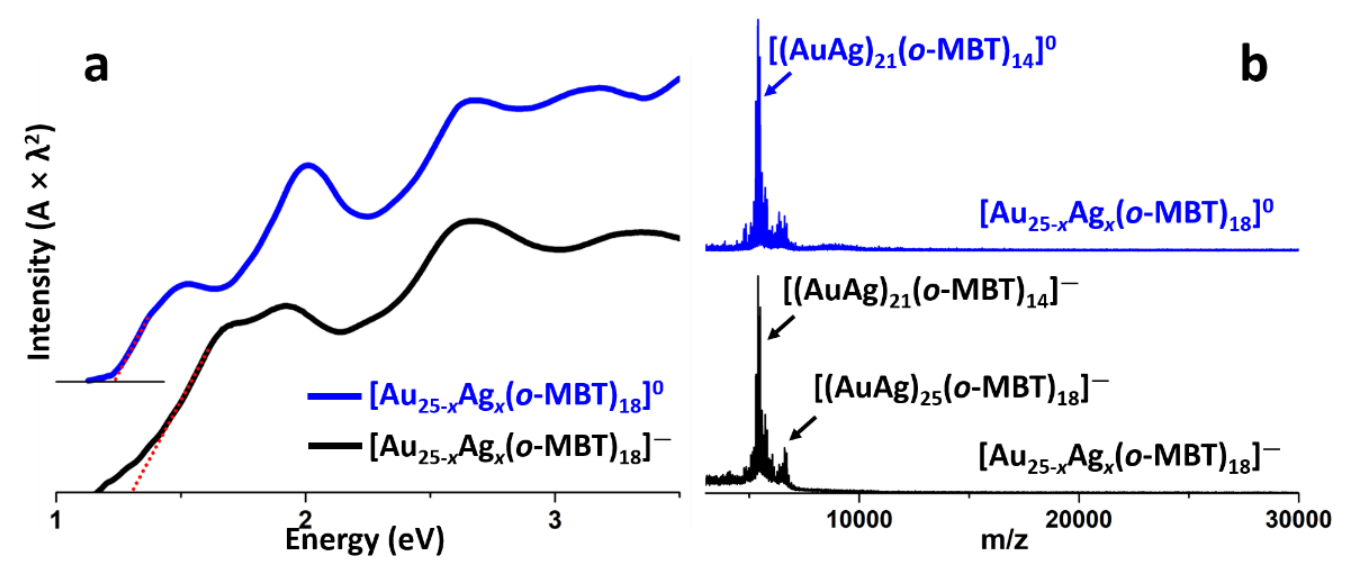

Figure S5. (A) UV-vis spectra on energy scale, and (B) MALDI-MS spectra of $\left[\mathrm{Au}_{25-x} \mathrm{Ag}_{x}(0-\right.$ MBT $\left.{ }_{18}\right]^{q}(q=-1$ (black) or 0 (blue)).

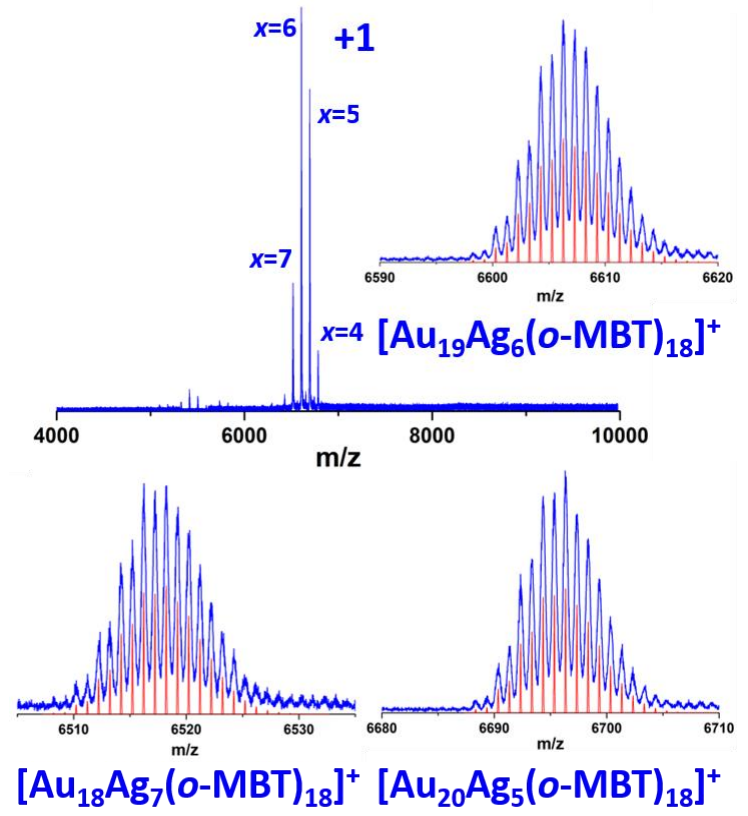

Figure S6. ESI-MS spectrum of $\left[\mathrm{Au}_{25-x} \mathrm{Ag}_{x}(0-\mathrm{MBT})_{18}\right]^{0}(x=4-7)$ and the experimental isotope patterns (blue) and calculated ones (red) for $\mathrm{x}=5$ to 7 . 


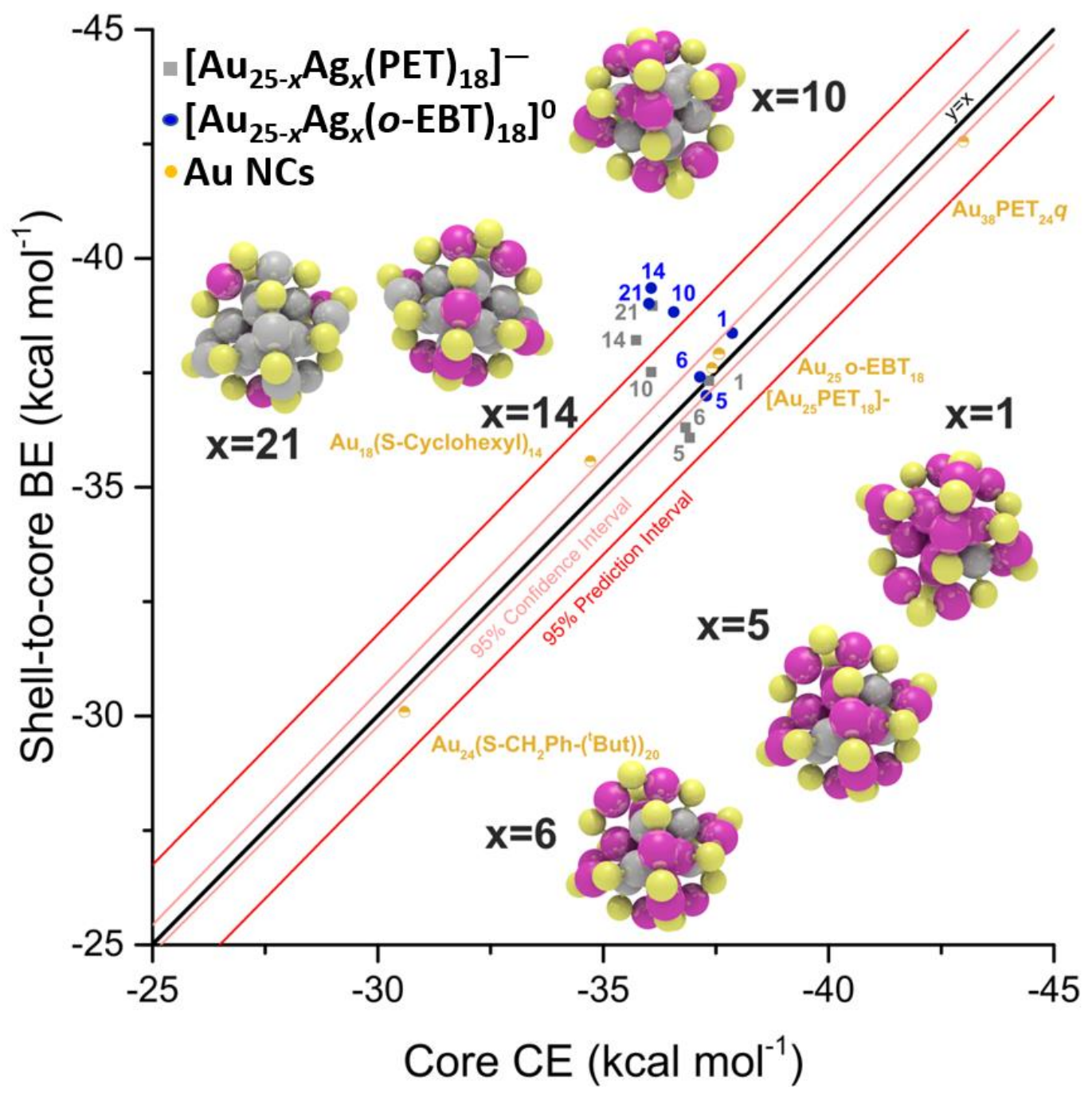

Figure S7. Shell-to-core binding energy (BE) vs. core cohesive energy (CE) for Au and Ag-

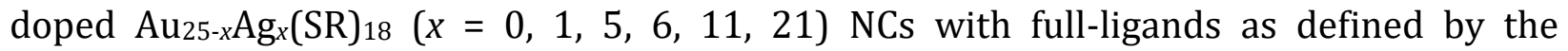
thermodynamic stability model. ${ }^{\mathrm{s}}$ Color labels: magenta $=\mathrm{Au}$, grey $=\mathrm{Ag}$, and yellow $=\mathrm{S}$. 


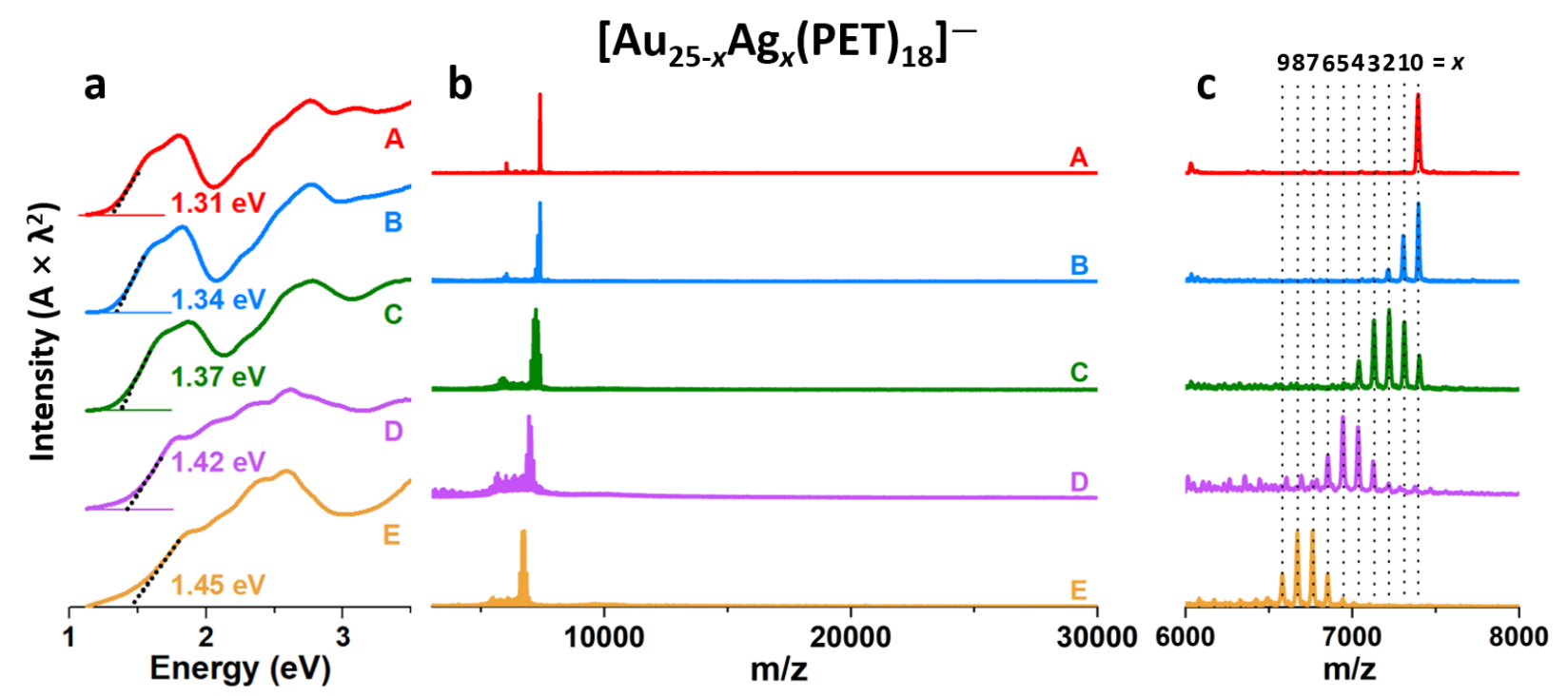

Figure S8. (a) UV-vis spectra on energy scale, (b/c) negative-ion MALDI-MS spectra (full range and zoom-in) of the $\left[\mathrm{Au}_{25-x} \mathrm{Ag}_{x}(\mathrm{PET})_{18}\right]^{-}$series, including $\mathrm{A}$ (red): $x=0$; $\mathrm{B}$ (blue): $x=$ 0-2; C (green): $x=0-6$; D (purple): $x=3-7$; and E (yellow): $x=5-9$.

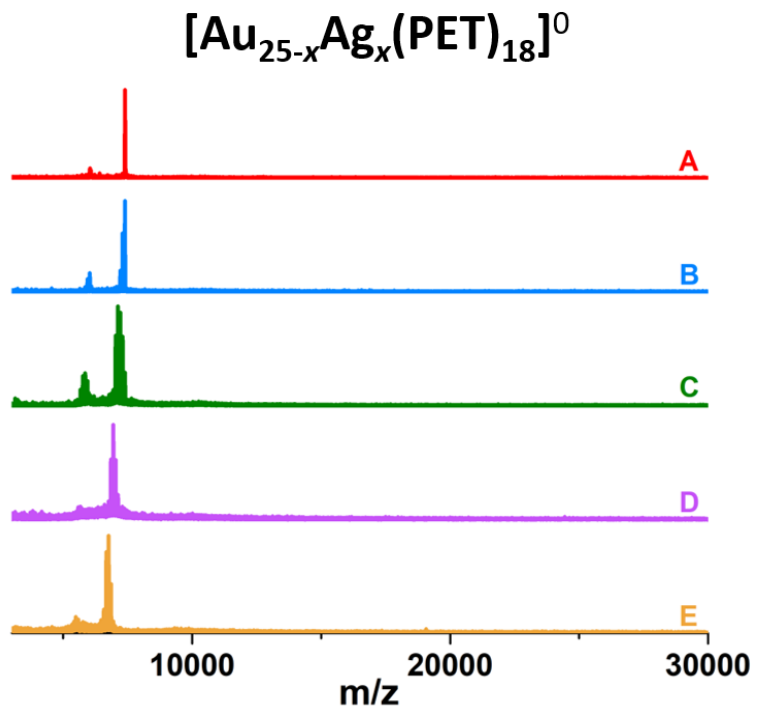

Figure S9. Positive-ion MALDI-MS spectra of the $\left[\mathrm{Au}_{25-x} \mathrm{Ag}_{x}(\mathrm{PET})_{18}\right]^{0}$ series, including $\mathrm{A}$ (red): $x=0$; B (blue): $x=0-2$; C (green): $x=0-6$; D (purple): $x=3-7$; and E (yellow): $x=5-9$. 

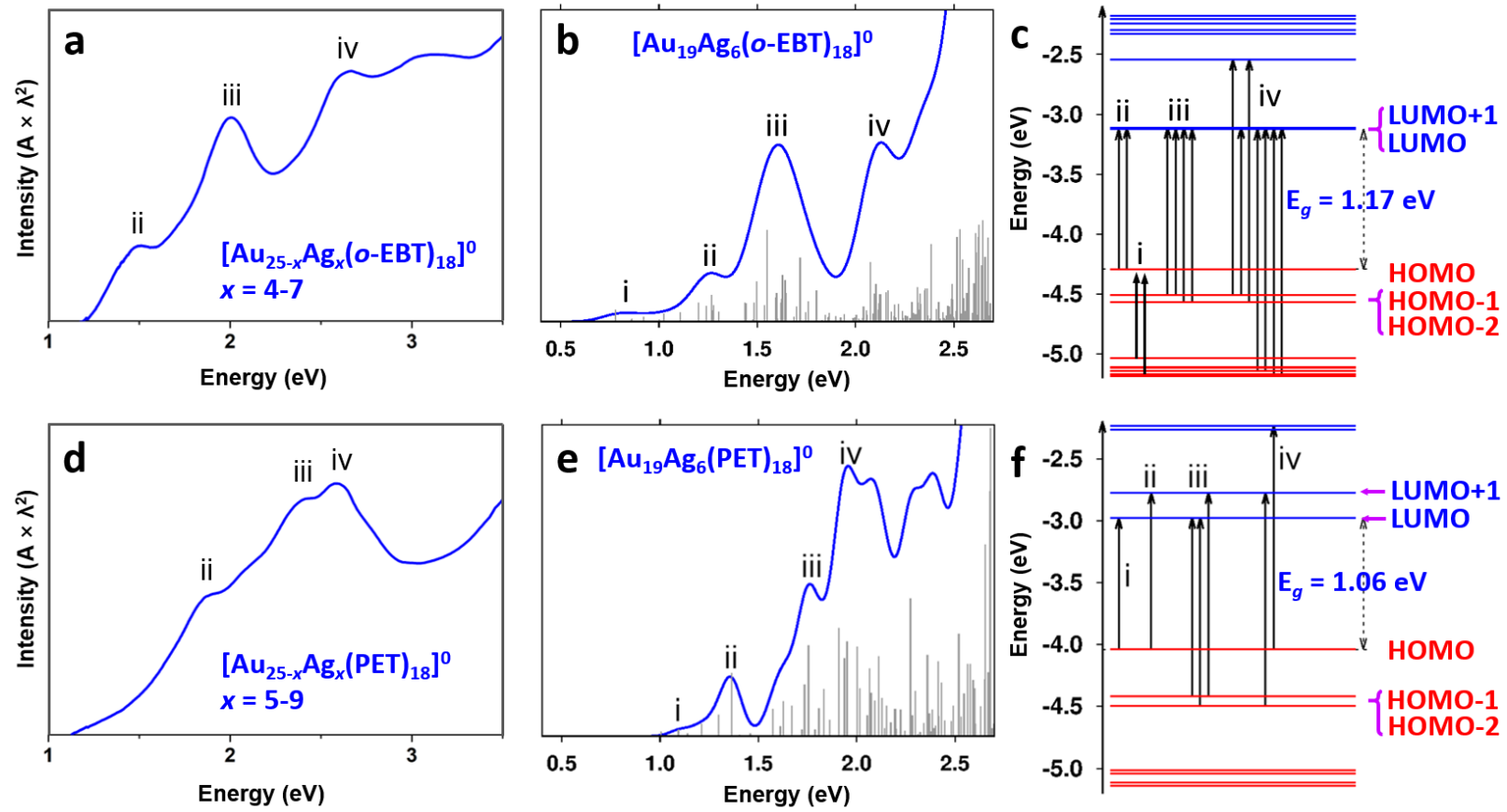

Figure S10. (a) Experimental spectrum of $\left[\mathrm{Au}_{25-x} \operatorname{Ag}_{x}(o-E B T)_{18}\right]^{0}(x=4-7)$, (b) calculated absorption spectrum of the most abundant species $\left[\mathrm{Au}_{19} \mathrm{Ag}_{6}(o-\mathrm{EBT})_{18}\right]^{0}$, and (c) corresponding KS diagram. (d) Experimental spectrum of $\left[\mathrm{Au}_{25-x} \mathrm{Ag}_{x}(\mathrm{PET})_{18}\right]^{0}(x=5-9)$, (e) calculated absorption spectrum of $\left[\mathrm{Au}_{19} \mathrm{Ag}_{6}(\mathrm{PET})_{18}\right]^{0}$, and (f) corresponding KS diagram.

Table S4. Electronic transitions contributing to the main peaks in the absorption spectra of $\left[\mathrm{Au}_{19} \mathrm{Ag}_{6}(o-\mathrm{EBT})_{18}\right]^{0}$ and $\left[\mathrm{Au}_{19} \mathrm{Ag}_{6}(\mathrm{PET})_{18}\right]^{0} \mathrm{NCs}$, respectively.

\begin{tabular}{|c|c|c|}
\hline & {$\left[\mathrm{Au}_{19} \mathrm{Ag}_{6}(o-\mathrm{EBT})_{18}\right]^{0}$} & {$\left[\mathrm{Au}_{19} \mathrm{Ag}_{6}(\mathrm{PET})_{18}\right]^{0}$} \\
\hline i & $\begin{array}{l}\text { HOMO-3 } \rightarrow \text { HOMO } \\
\text { HOMO-7 } \rightarrow \text { HOMO }\end{array}$ & HOMO $\rightarrow$ LUMO \\
\hline ii & $\begin{array}{l}\text { HOMO } \rightarrow \text { LUMO } \\
\text { HOMO } \rightarrow \text { LUMO+1 }\end{array}$ & HOMO $\rightarrow$ LUMO +1 \\
\hline iii & $\begin{array}{l}\text { HOMO-1 } \rightarrow \text { LUMO+1 } \\
\text { HOMO-1 } \rightarrow \text { LUMO } \\
\text { HOMO-2 } \rightarrow \text { LUMO+1 } \\
\text { HOMO-2 } \rightarrow \text { LUMO }\end{array}$ & $\begin{array}{l}\text { HOMO- } 1 \rightarrow \text { LUMO } \\
\text { HOMO- } 2 \rightarrow \text { LUMO } \\
\text { HOMO- } 1 \rightarrow \text { LUMO+1 }\end{array}$ \\
\hline iv & $\begin{array}{l}\text { HOMO-1 } \rightarrow \text { LUMO+2 } \\
\text { HOMO-1 } \rightarrow \text { LUMO+1 } \\
\text { HOMO-2 } \rightarrow \text { LUMO+2 } \\
\text { HOMO-6 } \rightarrow \text { LUMO } \\
\text { HOMO-6 } \rightarrow \text { LUMO+1 } \\
\text { HOMO-7 } \rightarrow \text { LUMO } \\
\text { HOMO-7 } \rightarrow \text { LUMO+1 }\end{array}$ & $\begin{array}{l}\text { HOMO }-2 \rightarrow \text { LUMO+1 } \\
\text { HOMO } \rightarrow \text { LUMO }+3\end{array}$ \\
\hline
\end{tabular}




\section{References}

(s1) APEX2, SAINT, and SADABS, Bruker AXS Inc.: Madison WI, USA, 2014.

(s2) G. Sheldrick, SHELXT - Integrated Space-Group and Crystal-Structure Determination. Acta. Cryst. 2015, A71, 3-8.

(s3) G. Sheldrick, Crystal Structure Refinement with SHELXL. Acta. Cryst. 2015, C71, 3-8.

(s4) Dolomanov, O. V.; Bourhis, L. J.; Gildea, R. J.; Howard, J. A.; Puschmann, H. OLEX2: A Complete Structure Solution, Refinement and Analysis Program. J. Appl. Crystallogr. 2009, 42, 339-341.

(s5) Petasis, D. T.; Hendrich, M. P. Quantitative Interpretation of Multifrequency Multimode EPR Spectra of Metal Containing Proteins, Enzymes, and Biomimetic Complexes. In Methods in Enzymology; Elsevier Inc. Waltham, 2015; Vol. 563, pp 171-208.

(s6) Abragam, A.; Bleaney, B. Electron Paramagnetic Resonance of Transition Ions; Oxford University Press, Oxford, 1970.

(s7) Perdew, J. P.; Burke, K.; Ernzerhof, M. Generalized Gradient Approximation Made Simple. Phys. Rev. Lett. 1996, 77, 3865-3868.

(s8) Mortensen, J. J.; Hansen, L. B.; Jacobsen, K. W. Real-Space Grid Implementation of the Projector Augmented Wave Method. Phys. Rev. B 2005, 71, 035109.

(s9) Enkovaara, J.; Rostgaard, C.; Mortensen, J. J.; Chen, J.; Dułak, M.; Ferrighi, L.; Gavnholt, J.; Glinsvad, C.; Haikola, V.; Hansen, H. A.; Kristoffersen, H. H.; Kuisma, M.; Larsen, A. H.; Lehtovaara, L.; Ljungberg, M.; Lopez-Acevedo, O.; Moses, P. G.; Ojanen, J.; Olsen, T.; Petzold, V.; Romero, N. A.; Stausholm-Møller, J.; Strange, M.; Tritsaris, G. A.; Vanin, M.; Walter, M.; Hammer, B.; Häkkinen, H.; Madsen, G. K. H.; Nieminen, R. M.; Nørskov, J. K.; Puska, M.; Rantala, T. T.; Schiøtz, J.; Thygesen, K. S.; Jacobsen, K. W. Electronic Structure Calculations with GPAW: A Real-Space Implementation of the Projector Augmented-Wave Method. J. Phys. Condens. Matter 2010, 22, 253202.

(s10) Taylor, M. G.; Mpourmpakis, G. Thermodynamic Stability of Ligand-Protected Metal Nanoclusters. Nat. Commun. 2017, 8:15988.

(s11) Taylor, M. G.; Mpourmpakis, G. Rethinking Heterometal Doping in Ligand-Protected Metal Nanoclusters. J. Phys. Chem. Lett. 2018, 9, 6773-6778.

(s12) Ahlrichs, R.; Bär, M.; Häser, M.; Horn, H.; Kölmel, C. Electronic structure calculations on workstation computers: The program system turbomole. Chem. Phys. Lett. 1989, 162, 165169.

(s13) Becke, A. D. Density-Functional Exchange-Energy Approximation with Correct Asymptotic Behavior. Phys. Rev. A 1988, 38, 3098-3100.

(s14) Perdew, J. P. Density-Functional Approximation for the Correlation Energy of the Inhomogeneous Electron Gas. Phys. Rev. B 1986, 33, 8822-8824.

(s15) Weigend, F.; Häser, M.; Patzelt, H.; Ahlrichs, R. RI-MP2: Optimized Auxiliary Basis Sets and Demonstration of Efficiency. Chem. Phys. Lett. 1998, 294, 143-152.

(s16) Weigend, F; Häser, M. RI-MP2: First Derivatives and Global Consistency. Theor. Chem. Acc. 1997, 97, 331-340. 